\title{
Influence of a bark-filler on the properties of PLA biocomposites
}

Piotr Borysiuk ${ }^{1, \star}$ (1), Piotr Boruszewski ${ }^{1}$ (D), Radosław Auriga ${ }^{1}$ (1), Leszek Danecki², Alicja Auriga ${ }^{3}$ (D), Katarzyna Rybak ${ }^{4}$ (D), and Małgorzata Nowacka ${ }^{4}$ (i)

${ }^{1}$ Institute of Wood Sciences and Furniture, Warsaw University of Life Sciences (WULS-SGGW), 159C Nowoursynowska St, 02-776 Warszawa, Poland

${ }^{2}$ Research and Development Centre For Wood-Based Panels, 10a Adama Mickiewicza St, 83-262 Czarna Woda, Poland

${ }^{3}$ Faculty of Environmental Management and Agriculture, West Pomeranian University of Technology Szczecin, 17 Słowackiego St, 71-434 Szczecin, Poland

${ }^{4}$ Department of Food Engineering and Process Management, Institute of Food Sciences, Warsaw University of Life Sciences (WULSSGGW), 159C Nowoursynowska St, 02-776 Warszawa, Poland

Received: 2 December 2020

Accepted: 4 February 2021

Published online:

18 February 2021

(C) The Author(s) 2021

\begin{abstract}
In this study, wood plastic composites (WPC) made of poly(lactic acid) PLA and a bark-filler were manufactured. Two degrees of bark comminution (10-35 mesh and over 35 mesh) and varied content of bark (40,50 and 60\%) were investigated. The studied panels were compared with analogically manufactured HDPE boards. The manufacture of composites involved two stages: at first, WPC granules with the appropriate formulation were produced using the extruder (temperatures in individual extruder sections were $170-180{ }^{\circ} \mathrm{C}$ ) and crushing using a hammer mill after cooling the extruded composite; secondly, the obtained granulate was used to produce boards with nominal dimensions of $300 \times 300 \times 2.5 \mathrm{~mm} 3$ by flat pressing in a mold, using a single daylight press at a temperature $200{ }^{\circ} \mathrm{C}$. The study proved that comminuted bark can be applied as a filler in PLA composites. However, an increase in bark content decreased mechanical properties (MOR, MOE) and deteriorated humidity resistance (high TS and WA) of the panels. Along with the increase in bark content, an increase in the contact angle of the composite surfaces and a decrease in the total surface energy were noted. It was also found that PLA composites have higher strength parameters and lower moisture resistance compared to HDPE composites with the same bark content.
\end{abstract}

Communicated by Handling Editor: Stephen Eichhorn.

Address correspondence to E-mail: piotr_borysiuk@sggw.edu.pl 


\section{GRAPHICAL ABSTRACT}

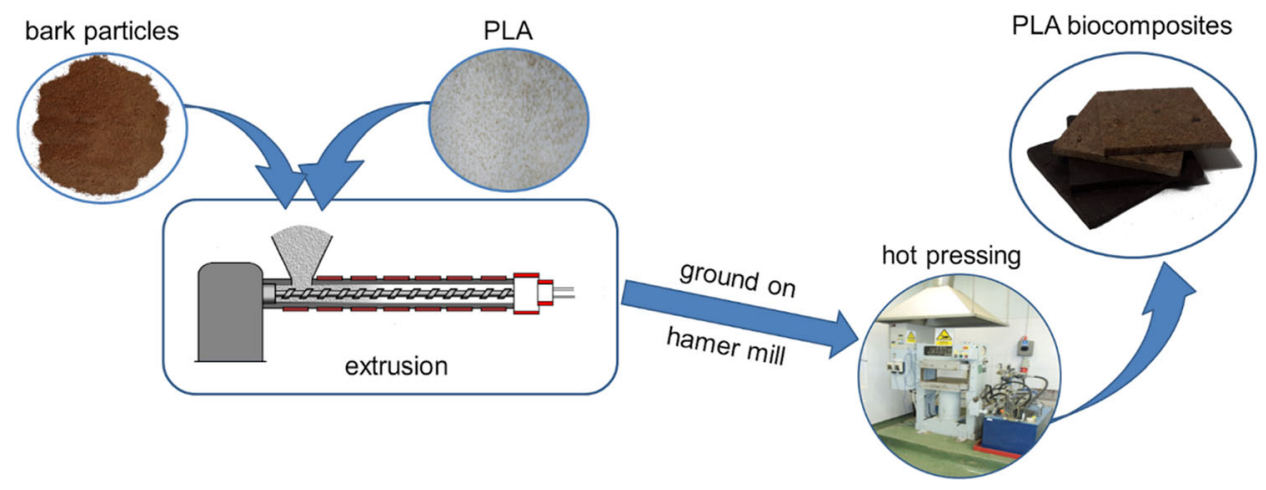

\section{Introduction}

The dynamic development of wood plastic composites (WPC) technology involves the introduction of new material solutions for the matrix and the filler. In both cases, the biodegradability of raw materials is essential. Nowadays a significant amount of WPC composites known as biocomposites is produced with the addition of polymers derived from fossil fuels. These include primarily polyethylene PE (used in decking and construction, consumer goods), polypropene PP (used in automotive, construction, consumer goods) or polyvinyl chloride PVC (used in decking and construction) [1]. However, these materials are not biodegradable; thereby, it makes it debatable whether these WPC composites should be included in the family of biocomposite materials.

Biodegradable thermoplastics such as poly(lactic acid) (PLA) or polyhydroxyalkanoate (PHA) can be used in the production of WPC composites. PHA slowly decomposes into water and carbon dioxide under activity of microorganisms present in soil, sewage or silt; anaerobic conditions are particularly favorable for this process. That makes PHA applicable in packaging and components with a short shelf life. In turn, PLA is less biodegrade under natural conditions; therefore, it can be applied in components with a long service life. Environmentally safe degradation of PLA occurs during composting [2]. PLA is by far the most widely studied and applied biodegradable aliphatic polyester in history.
Regarding its advantages it is a leading biomaterial for multiple applications in medicine and in the industry replacing conventional petrochemical polymers [3]. However, its sensitivity to moisture, susceptibility to aging, limited impact strength and high rigidity in some applications [4] result in frequent modification of PLA. One of the modifications involves introduction of fillers (manufacturing WPC composite), especially in construction applications.

The most popular natural fillers are wood materials in the form of wood flour or wood fibers. The size of filler's particles depends on the purpose of the composite [5]. In general, there are no limitations to the use of different types of wood as fillers for polymer composites [6]. However, due to the simpler anatomical structure and higher ratio of length to diameter of the elements of anatomical structure, it is preferable to use coniferous species [7]. Saputra et al. [8] and Shebani et al. [9] reported a negative impact of extractive substances content on bonding wood fibers with a polymer matrix and on the thermal stability of composites. Aside solid wood, WPC composites production can also apply sawdust and flour, post-use wood materials such as particleboards and MDF [10] or waste paper [11, 12]. Particles obtained from plant materials other than wood can be also utilized as fillers for WPC composites.

Bark is a common waste in the production of wood and wood materials. The main two trends in bark applications are: bark obtained in a special way used in the production of medicines, cosmetics, tannins, dyes, cork $[13,14]$ and waste bark for composting or 
incineration $[13,15]$. The efficiency of the incineration process is low due to the typical for bark high humidity (34-40\% during dry summer, and up to $60 \%$ in winter) and a high content of mineral substances constituting ash after burning (more than 2\%) compared to wood [13]. Bark can be utilized as an alternative raw material for the production of particleboard [15, 16]. The tests generally showed a decrease in panel strength parameters along with an increase in the bark share. Shredded bark is also a potential filler in the production of WPC composites [17-20]. Yemele et al. [18] showed that WPC composites filled with bark have lower strength parameters compared to analogous composites filled with wood flour. Also, other researchers reported a decline in the mechanical properties of WPC composites filled with bark [17, 20]. In turn, the use of bark as a filler in WPC composites improves their physical properties related to moisture absorption. Gozdecki et al. [19] and Najafi et al. [21] indicated that the increase in bark content in WPC composites decreases their swelling and water absorption.

Natural fillers have also been used in research on biodegradable WPC composites applying PLA as a polymer matrix. Among them were: wood fibers [22-24], wood flour (WF) [25, 26], cellulose nanofibrils [27], cork [25, 28], bamboo fiber [29], abaca fibers [30], rubber wood sawdust [31], hemp fibers [32]. In general, authors report an improvement in the mechanical properties of PLA composites filled with wood fibers with a filler content of up to $20 \%$ [23] or $30 \%$ [22]. Csizmadia et al. [33] showed a beneficial effect of wood fiber modification with phenolformaldehyde resin on improving strength properties and reducing water absorption in the production of PLA-based composites. In turn, Andrzejewski et al. [25] showed the beneficial effect of cork filler (up to $30 \%$ ) on the dimensional stability of PLA composites in the presence of moisture. However, the use of wood flour as a filler affects resistance of PLA composites to moisture [26].

As part of this study, the effect of the addition of bark as a filler to the PLA matrix in the production of biodegradable WPC composite was determined. This type of composite variant has not yet been studied. For comparison, an analogous WPC composites based on high-density polyethylene (HDPE) matrix were made. Three levels of bark content at two degrees of bark comminution were investigated. The manufacture of the composites involved two stages: extrusion and flat pressing. The effect of bark addition was analyzed in the context of selected physical and mechanical properties of composites.

\section{Experimental}

Twelve variants of WPC composite panels (Table 1) were manufactured based on two types of polymer matrices: polylactic acid-PLA (Ingeo ${ }^{\mathrm{TM}}$ Biopolymer 2003D, NatureWorks LLC, Minnetonka, MN, USA), and high-density polyethylene-HDPE (Hostalen GD 7255, Basell Orlen Polyolefins Co., Płock, Poland). The filler was a crushed pine bark supplied from a sawmill. The bark was dried to a moisture content of $5 \%$ and then mechanically ground and sorted into two variants:

1. Particles passing through a 2-mm sieve (approx. 10 mesh) and remaining on a $0.49-\mathrm{mm}$ sieve (approx. 35 mesh)—Fig. 1a.

2. Particles passing through a 0.49 -mm sieve (over 35 mesh)-Fig. $1 b$.

No other additives commonly used in the production of WPC such as compatibilizers were applied in the study, due to comparative assessment of combinations: PLA—bark and HDPE-bark.

The manufacture of composites involved two stages. At first, WPC granules with the appropriate formulation (Table 1) were produced using the Leistritz Extrusionstechnik GmbH, Nürnberg, Germany, extruder (temperatures in individual extruder sections were $170-180^{\circ} \mathrm{C}$ ). The obtained continuous composite web was ground on a hammer mill. Secondly, the obtained granulate was used to produce boards with nominal dimensions of $300 \times 300 \times 2.5$ $\mathrm{mm}^{3}$ by flat pressing in a mold, using a single daylight press at a temperature of $200{ }^{\circ} \mathrm{C}$ and a maximum unit pressing pressure $p_{\max }=1.25 \mathrm{MPa}$ (pressure during pressing, along with plasticization of the material, was gradually increased from 0 to $\left.p_{\max }\right)$. Pressing time was $6 \mathrm{~min}$. After hot pressing, the plates were cooled in the mold for $6 \mathrm{~min}$ in a cold press (approx. temp. $20^{\circ} \mathrm{C}$ ). Eventually, the manufactured panels were conditioned at ambient temperature and humidity for 7 days under laboratory conditions $\left(20 \pm 2{ }^{\circ} \mathrm{C}, 65 \pm 5 \%\right.$ humidity).

The following physical and mechanical properties of the boards were tested: 
Table 1 Characteristics of the composition of individual variants of composites

\begin{tabular}{lllll}
\hline Variant & Matrix & Share of matrix & Bark share & \\
\cline { 4 - 5 } & & & Small particles over 35 mesh & Large particles 10-35 mesh \\
\hline I & PLA & 60 & - & 40 \\
II & PLA & 50 & - & 50 \\
III & PLA & 40 & - & 60 \\
IV & PLA & 60 & 40 & - \\
V & PLA & 50 & 50 & - \\
VI & PLA & 40 & 60 & - \\
VII & HDPE & 60 & - & 40 \\
VIII & HDPE & 50 & - & 50 \\
IX & HDPE & 40 & - & 60 \\
X & HDPE & 60 & 40 & - \\
XI & HDPE & 50 & 50 & - \\
XII & HDPE & 40 & 60 & - \\
\hline & & & &
\end{tabular}

Figure 1 Particles of bar: a Large particles $(10-35$ mesh). b Small particles (over 35 mesh).

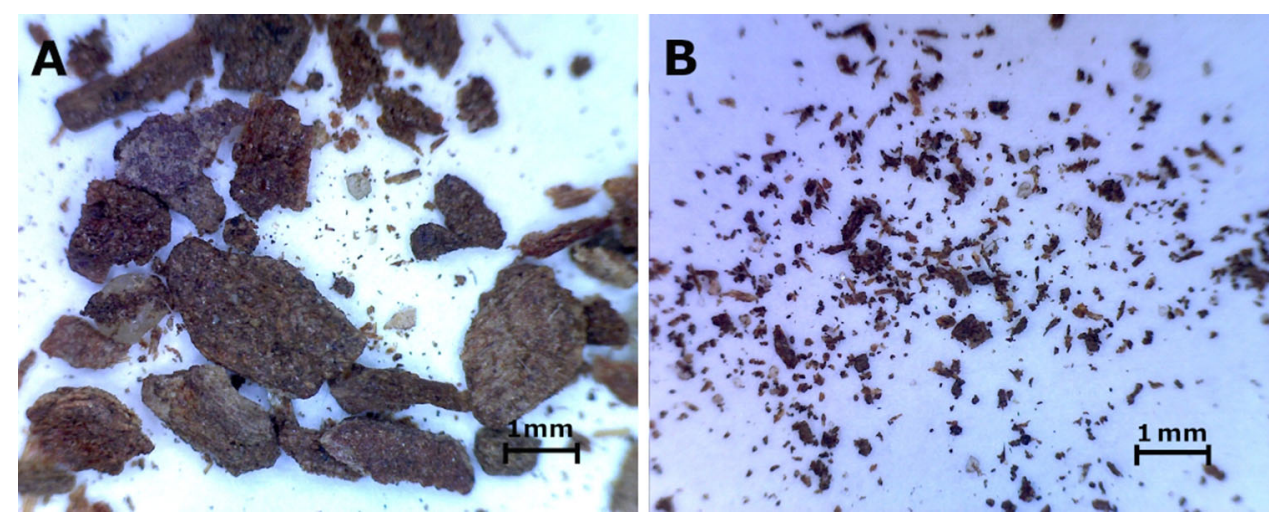

- Density according to EN 323:1999 and density profile using Laboratory Density Analyser DAX GreCon (Fagus-Grecon Greten GmbH \& Co. KG, Alfeld, Germany). Density measurement was made every $0.02 \mathrm{~mm}$ at the measurement speed of $0.05 \mathrm{~mm} / \mathrm{s}$.

- Modulus of rupture (MOR) and modulus of elasticity (MOE) according to EN 310:1994 [34].

- Screw holding (SH) according to EN 320:2011 [35].

- Thickness swelling (TS) and water absorption (WA) after 2-h and 24-h immersion in wateraccording to EN 317:1999 [36].

- Wettability (contact angle) and surface free energy. Contact angle $(\theta)$ based on the sessile drop method and performed on a Phoenix 300 (Surface Electro Optics, Suwon City, Korea) contact angle analyzer, equipped with microscopic lenses and digital camera was measured. The distilled water and diiodomethane were used as reference liquids for wettability calculations. The values of contact angles were determined after
$45 \mathrm{~s}$ of application of drops of liquid onto the surface of the reference (the water). For each type of board (on both sides) ten droplets were measured.

- The surface free energy was determined using the Owens-Wendt (1969) method.

Tests involved ten replicates of each variant. Additionally, the microscopic images of samples using a Tabletop Microscope TM3000 microscope (Hitachi Ltd., Tokyo, Japan) were taken.

Statistical analysis of the results was carried out using Statistica version 13 (TIBCO Software Inc., CA, USA). The analysis of variance (ANOVA) was used to test $(\alpha=0.05)$ for significant differences between factors. A comparison of the means was made using Tukey's test, with $\alpha=0.05$. In addition, principal component analysis (PCA) was performed to describe the patterns of covariant among the examined traits. 


\section{Results and discussion}

The tested panels were characterized by densities ranging between 1114 and $1182 \mathrm{~kg} / \mathrm{m}^{3}$ for PLA matrix and 1051 and $1105 \mathrm{~kg} / \mathrm{m}^{3}$ for HDPE. The average density values for individual panel variants are presented in Table 2 . The density variation for individual variants within the same matrices (PLA or HDPE) did not exceed 6\%. Also, no effect of filler's particle size was observed. Moreover, the PLA boards consisting the same share and size of filler particles had higher density by 1 to $11 \%$, respectively. This is due to the higher density of PLA matrix compared to HDPE matrix. Similar dependencies were observed by Andrzejewski et al. (2019) [25] studying WPC composites based on PLA and PP. The authors also pointed to a decrease in the density of PLA-based composites with an increase in cork content. A similar phenomenon was recorded in the present study for bark content of $40-50 \%$. It should be added, however, that a further increase in the bark content (up to 60\%) would increase the density of the composite. All variants of the tested panels were characterized by an even distribution of density across the cross section (Fig. 2). Density differences across the thickness of individual panels generally did not exceed $100 \mathrm{~kg} / \mathrm{m}^{3}$. This demonstrates good homogenization of composite components and even distribution of filler particles in the polymer matrix.

The strength parameters of the composites presented in Table 3 were higher for PLA panels compared to the HDPE panels. This is due to the greater rigidity of PLA than polyolefins [37].

The increase in bark content regardless of its size resulted in a significant decrease in the MOR value. Similar relationships demonstrated Gozdecki et al., Yemele et al. or Andrzejewski et al. [18, 19, 25], where the authors while studying composites with a lower bark content (max. up to $40 \%$ ) recorded a nearly sevenfold decline in MOR for PLA composites with small particles of bark, and the maximum decrease was about $60 \%$. This relationship was not found in the present study for HDPE composites. The addition of bark to HDPE regardless the size of particles resulted in a comparable decrease in strength, maximum $30 \%$.

The increase in bark content from 40 to $60 \%$ significantly affected the decrease in MOE values only for PLA composite with the addition of small particles of bark. At the same time, higher MOE values were recorded for PLA matrix composites with large particles of bark compared to small particles. An opposite effect was obtained for HDPE matrix composites which showed significantly higher values for small particle. These results are borne out by two other studies: Yemele et al. and Çetina et al. [18, 38].

The increase in the content of bark particles in the tested composites also influenced the decrease in $\mathrm{SH}$ value, and it varied depending on the particles size. Similarly as in the case of MOE, the largest decrease was recorded for PLA matrix composites with the addition of small particles of bark. Gozdecki and Kociszewski [39] when studying PP-based composites observed a decrease in $\mathrm{SH}$ value with an increase in wood flour content. In turn, Falk et al. [40] found that for composites based on LDPE and PP and wood flour the increase in lignocellulosic filler content did not affect $\mathrm{SH}$ values.

When analyzing the strength properties, it must be emphasized that small particles of bark have about 20 times larger specific surface area in comparison with large particles, which significantly increases the potential contact surface between the filler and the matrix, as well as increases their dispersion in the

Table 2 The density of manufactured panels according to variants

\begin{tabular}{lllllll}
\hline Matrix & Bark share [\%] & \multicolumn{2}{l}{ Large particles of bark } & & \multicolumn{2}{l}{ Small particles of bark } \\
& & Average density $\left[\mathrm{kg} / \mathrm{m}^{3}\right]$ & Standard dev. $\left[\mathrm{kg} / \mathrm{m}^{3}\right]$ & & Average density $\left[\mathrm{kg} / \mathrm{m}^{3}\right]$ & Standard dev. $\left[\mathrm{kg} / \mathrm{m}^{3}\right]$ \\
\hline PLA & 40 & 1167 & 47 & 1171 & 41 \\
PLA & 50 & 1159 & 65 & 1114 & 46 \\
PLA & 60 & 1182 & 58 & 1123 & 51 \\
HDPE & 40 & 1051 & 24 & 1053 & 26 \\
HDPE & 50 & 1078 & 25 & 1105 & 27 \\
HDPE & 60 & 1094 & 29 & 1077 & 38 \\
\hline
\end{tabular}


Figure 2 Density profiles of manufactured panels.
Table 3 Mechanical properties of manufactured boards

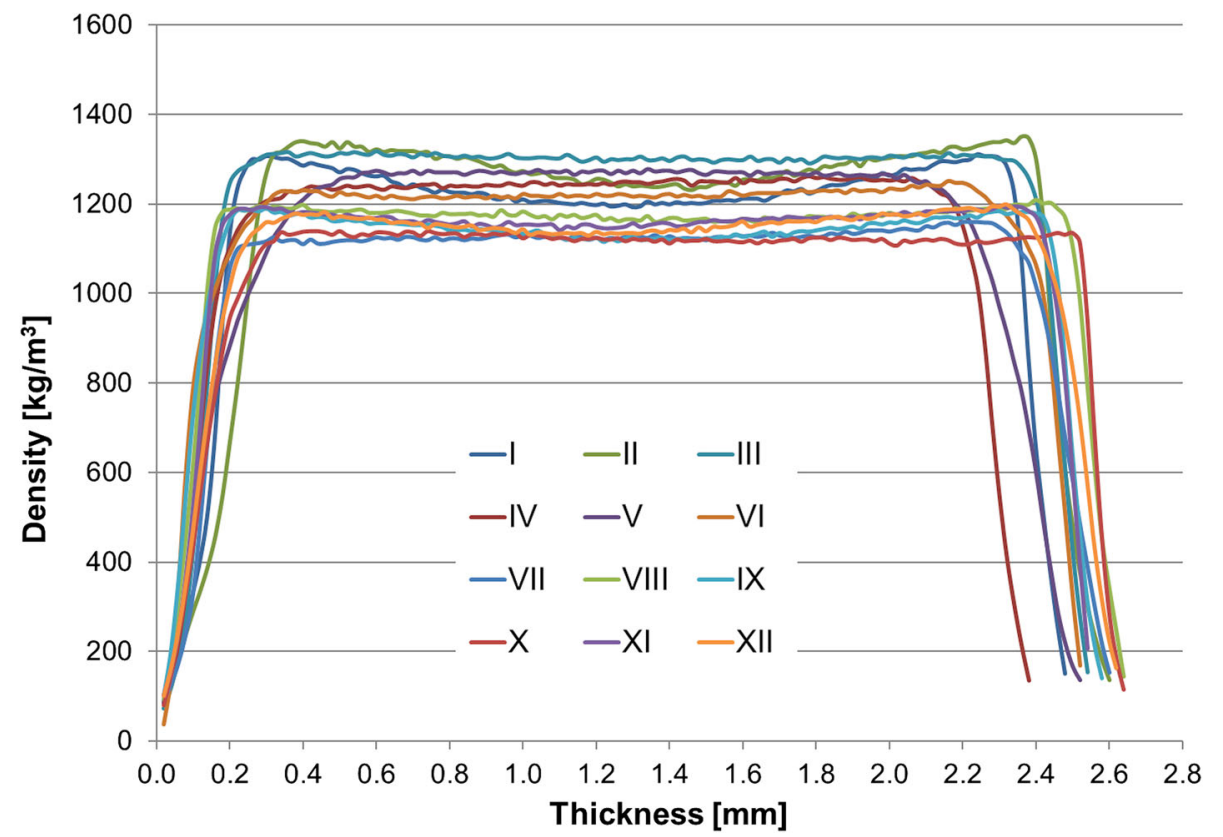

\begin{tabular}{|c|c|c|c|c|c|c|}
\hline \multirow[t]{2}{*}{ Share of bark [\%] } & \multicolumn{2}{|l|}{ PLA } & \multirow[t]{2}{*}{ Average } & \multicolumn{2}{|l|}{ HDPE } & \multirow[t]{2}{*}{ Average } \\
\hline & $\mathrm{L}$ & $\mathrm{S}$ & & $\mathrm{L}$ & $\mathrm{S}$ & \\
\hline \multicolumn{7}{|l|}{$\operatorname{MOR}\left[\mathrm{N} / \mathrm{mm}^{2}\right]$} \\
\hline 40 & $33.19^{\mathrm{ab}}$ & $34.21^{\mathrm{a}}$ & $33.7^{\mathrm{A}}$ & $20.08^{\mathrm{de}}$ & $20.83^{\mathrm{d}}$ & $20.46^{\mathrm{CD}}$ \\
\hline 50 & $28.24^{\mathrm{c}}$ & $16.67^{\mathrm{ef}}$ & $22.45^{\mathrm{BC}}$ & $19.03^{\mathrm{de}}$ & $18.21^{\mathrm{de}}$ & $18.62^{\mathrm{D}}$ \\
\hline 60 & $30.62^{\mathrm{bc}}$ & $14.27^{\mathrm{f}}$ & $23.35^{\mathrm{B}}$ & $14.31^{\mathrm{f}}$ & $16.86^{\mathrm{ef}}$ & $15.58^{\mathrm{E}}$ \\
\hline Average & $30.68^{1}$ & $22.25^{2}$ & - & $17.81^{3}$ & $18.63^{3}$ & - \\
\hline \multicolumn{7}{|l|}{$\operatorname{MOE}\left[\mathrm{N} / \mathrm{mm}^{2}\right]$} \\
\hline 40 & $3597^{\mathrm{a}}$ & $3669^{\mathrm{a}}$ & $3634^{\mathrm{A}}$ & $1463^{\mathrm{e}}$ & $1854^{\text {cde }}$ & $1659^{\mathrm{C}}$ \\
\hline 50 & $4049^{a}$ & $2990^{\mathrm{b}}$ & $3520^{\mathrm{AB}}$ & $1771^{\text {cde }}$ & $1895^{\text {cde }}$ & $1836^{\mathrm{C}}$ \\
\hline 60 & $3944^{\mathrm{a}}$ & $2345^{\mathrm{c}}$ & $3233^{\mathrm{B}}$ & $1595^{\text {cde }}$ & $2035^{\mathrm{cd}}$ & $1827^{\mathrm{C}}$ \\
\hline Average & $3864^{1}$ & $3048^{2}$ & - & $1605^{4}$ & $1928^{3}$ & - \\
\hline \multicolumn{7}{|l|}{$\mathrm{SH}[\mathrm{N}]$} \\
\hline 40 & $219.55^{\mathrm{a}}$ & $228.36^{\mathrm{a}}$ & $224.19^{\mathrm{A}}$ & $151.72^{\mathrm{bc}}$ & $154.29^{\mathrm{bc}}$ & $153.00^{\mathrm{B}}$ \\
\hline 50 & $164.96^{\mathrm{b}}$ & $99.68^{\mathrm{d}}$ & $132.32^{\mathrm{C}}$ & $145.71^{\mathrm{bc}}$ & $150.07^{\mathrm{bc}}$ & $147.89^{\mathrm{B}}$ \\
\hline 60 & $215.35^{\mathrm{a}}$ & $96.63^{\mathrm{d}}$ & $159.11^{\mathrm{B}}$ & $98.90^{\mathrm{d}}$ & $136.55^{\mathrm{c}}$ & $117.73^{C}$ \\
\hline Average & $199.28^{1}$ & $143.11^{2.3}$ & - & $132.11^{3}$ & $146.97^{2}$ & - \\
\hline
\end{tabular}

$L$ large particles of bark, $S$ small particles of bark, $A, B, \ldots, a, b, \ldots, 1,2, \ldots$ homogenous group matrix. At the same time, the matrix structure is thinner, which with a rigid but brittle PLA material can also affect the strength of composites. Faludi et al. [41] reported that the decrease in strength of composites with the addition of lignocellulosic fillers on one hand may be due to limited interfacial adhesion, which depends on the difference in surface energy of the combined components, and on the other hand it is the effect of cracks occurring in the filler itself. The tested PLA boards were characterized by free surface energy in the range from 51.676 to $37.755 \mathrm{~mJ} \cdot \mathrm{m}^{-2}$, while the value decreased with the increase in the content and degree of bark fragmentation (Table 4). There are no data in the literature regarding the surface energy of clean bark. However, taking into account the results obtained for the tested panels and similar literature data on the surface energy of PLA and wood [42, 43], it can be assumed that the decrease in composites strength noted in the present 
study is mainly affected by susceptibility of bark for cracking.

Figure 3 shows photographs taken with the use of a scanning electron microscope, enabling observation of the topography of individual variants of the tested composites, in which, regardless of the share and size of the bark particles, cracks are visible in the lignocellulosic particles. The cracks are formed at several stages of the process, e.g., when material is conveyed by the screw or forced through the die in the extruder [44].
All the three variable factors, i.e., matrix type, filler particles size and filler share, had a significant effect on the MOR, MOE and $\mathrm{SH}$ values of the manufactured composites (Table 5). However, the percentage of contribution (P\%) for individual factors as well as for their interactions was varied.

The most significant factor that affected MOR values was the type of matrix $(P=29.36 \%)$, followed by the share of bark $(P=22.65 \%)$ and the size of bark particles $(P=7.64 \%)$. The total percentage of contribution for these factors was $59.65 \%$, which proves their importance. A significant interaction was
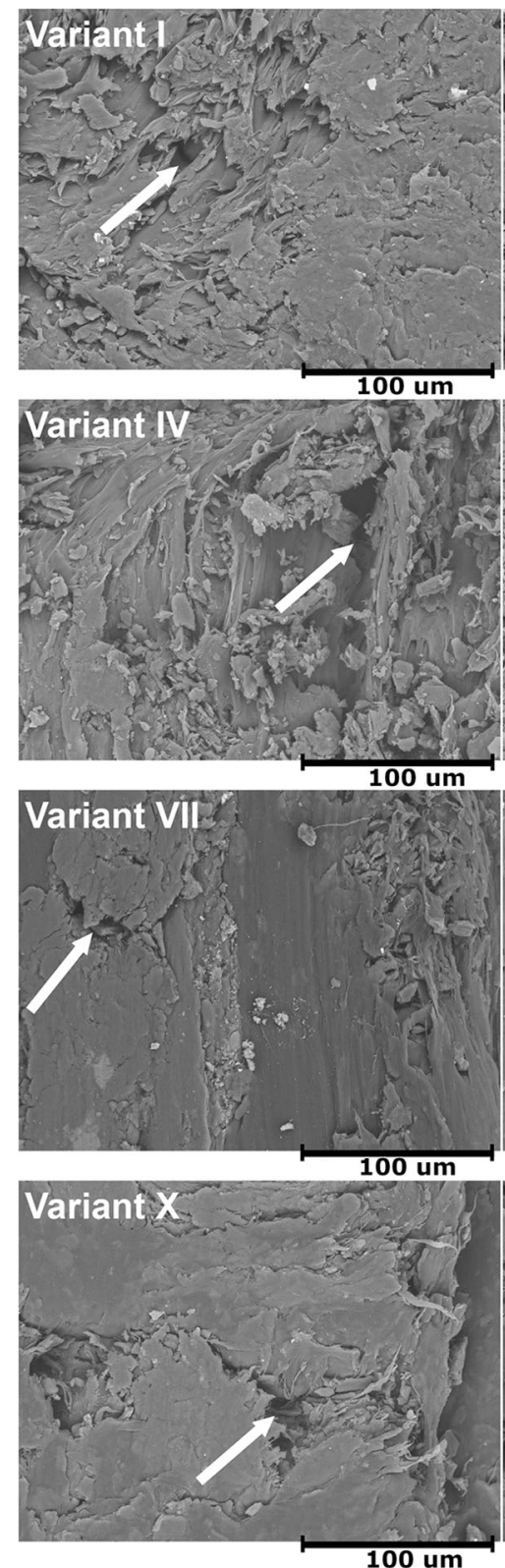
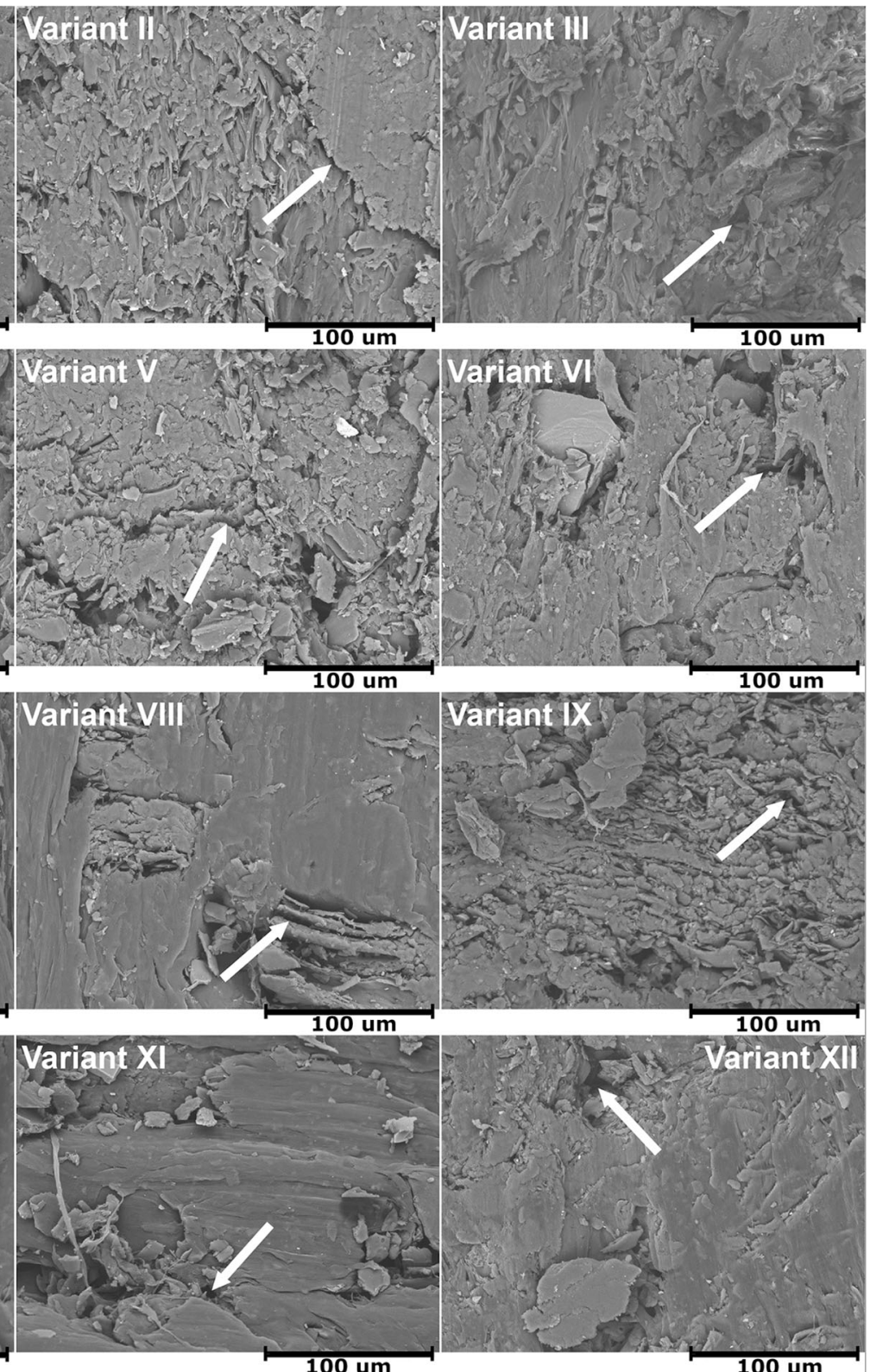

Figure 3 Surface topography of individual variants of the tested composites. 
Table 4 Contact angle and surface free energy of manufactured composites

\begin{tabular}{lllll}
\hline Variant & Contact angle of water $\left[^{\circ}\right]$ & \multicolumn{3}{l}{ Surface free energy $\left[\mathrm{mJ} \mathrm{m}^{-2}\right]$} \\
\cline { 3 - 4 } & & $\gamma^{\text {tot }}$ & $\gamma^{\mathrm{D}}$ & $\gamma^{\mathrm{P}}$ \\
\hline I & 68.9 & 51.676 & 45.603 & 6.073 \\
II & 78.6 & 44.331 & 41.181 & 3.150 \\
III & 71.8 & 47.363 & 42.167 & 5.196 \\
IV & 70.3 & 49.404 & 44.305 & 5.100 \\
V & 85.5 & 38.293 & 36.527 & 1.767 \\
VI & 98.8 & 37.755 & 37.754 & 0.001 \\
VII & 65.8 & 50.708 & 43.200 & 7.508 \\
VIII & 61.8 & 54.057 & 44.949 & 9.107 \\
XI & 66.1 & 52.903 & 45.826 & 7.078 \\
X & 69.1 & 49.382 & 42.891 & 6.492 \\
IX & 72.7 & 48.521 & 43.803 & 4.718 \\
XII & 71.2 & 48.769 & 43.331 & 5.438 \\
\hline
\end{tabular}

demonstrated between the matrix type and the bark particle size $(11.05 \%)$. Interestingly, the influence of filler particle size on MOR was less than the effect of factors not considered in this study (error $=9.27 \%$ ).

Type of matrix was found to have the highest percentage share $(68.17 \%)$ of influence on MOE values. Interestingly, the share of bark filler indicated no significant effect on the parameter. The effect of filler particles size on the MOE values and the effect of interaction between the share of bark-filler and the filler particles size were less than the effect of factors not considered in this study (error $=12.77 \%$ ).

When analyzing the impact of individual factors on $\mathrm{SH}$ values, all sources of variance were significant. In contrast to MOR and MOE, the most crucial factor in determining the $\mathrm{SH}$ value was the share of bark-filler $(P=25.29 \%)$, followed by the interactions between matrix type and size of bark particles $(P=15.30 \%)$ and interaction between matrix type and share of bark $(P=14.61 \%)$. The error value $(P=11.35 \%)$ was higher than the $P$ values of the rest tested factors; this indicates that untested factors had a greater influence on $\mathrm{SH}$.

The physical parameters of the manufactured composites are present in Table 6. The PLA-matrix panels were generally characterized by lower water resistance (TS and WA) compared to HDPE-matrix panels. The difference was particularly noticeable after immersion for $24 \mathrm{~h}$ in the water, regardless of the bark content and the filler particle size. Moisture penetration into the internal structure of the composite occurs through lignocellulosic particles, which increase their dimensions during this process. This deteriorates the contact between the filler and the polymer mesh, and the effect being greater to stiffer PLA. The HDPE matrix with good flexibility can partially absorb changes in the dimensions of the filler. An increase in the filler's compactness as well as an increase in its particle size results in a significant increase in TS and WA values. This is due to the greater availability of lignocellulosic filler particles on the composite surface $[45,46]$. It is also confirmed by the lower contact angles of the surface with water when larger filler particles are used (Table 4). It is noteworthy that bark contains hydrophobic suberin $[47,48]$ which can reduce the wettability of the surface.

The most significant influence on TS and WA of tested boards had type of matrix and the share of bark-filler (Table 7). The total percentage of the impact of these factors after $24 \mathrm{~h}$ of immersion in water was over $55 \%$. The treatment revealed also that size of bark particles had a minor influence on TS and WA $(P=5.39 \%$ and $P=1.91 \%$, respectively). It should be noted that especially during the TS test error values for $2 \mathrm{~h}$ and $24 \mathrm{~h}$ were considerably high, which may have been caused by other external factors excluded from the research. The greatest impact on TS and WA out of tested interactions had the interaction among the type of matrix and the filler particle size and the filler content.

PCA was performed for further data evaluation. On the charge distribution graph (Fig. 4), the points denoting Variants I and IV have positive coordinates on both axes $\mathrm{p} 1$ and p2. Thus, they are at a small distance from each other and the points indicating 
Table 5 ANOVA for selected factors affecting MOR, MOE and $\mathrm{SH}$ of manufactured composites

Table 6 Selected physical properties of manufactured boards

\begin{tabular}{|c|c|c|c|c|c|c|}
\hline \multirow[t]{2}{*}{ Source of variance } & \multicolumn{2}{|l|}{ MOR } & \multicolumn{2}{|l|}{ MOE } & \multicolumn{2}{|l|}{$\mathrm{SH}$} \\
\hline & $p$ & $P(\%)$ & $p$ & $P(\%)$ & $p$ & $P(\%)$ \\
\hline a & 0.000 & 29.36 & 0.000 & 68.17 & 0.000 & 11.11 \\
\hline $\mathrm{b}$ & 0.000 & 7.64 & 0.000 & 1.82 & 0.000 & 5.40 \\
\hline $\mathrm{c}$ & 0.000 & 22.65 & 0.058 & 0.72 & 0.000 & 25.29 \\
\hline$a \times b$ & 0.000 & 11.05 & 0.000 & 8.58 & 0.000 & 15.30 \\
\hline$a \times c$ & 0.000 & 7.23 & 0.001 & 1.70 & 0.000 & 14.61 \\
\hline $\mathrm{b} \times \mathrm{c}$ & 0.000 & 5.74 & 0.000 & 3.21 & 0.000 & 4.46 \\
\hline $\mathrm{a} \times \mathrm{b} \times \mathrm{c}$ & 0.000 & 7.06 & 0.000 & 3.02 & 0.000 & 12.47 \\
\hline Error & & 9.27 & & 12.77 & & 11.35 \\
\hline
\end{tabular}

$a$ matrix type/composite, $b$ size of bark particles, $c$ share of bark-filler, $p$ probability of error, $P$ percentage of contribution

\begin{tabular}{|c|c|c|c|c|c|c|}
\hline \multirow[t]{2}{*}{ Share of bark [\%] } & \multicolumn{2}{|l|}{ PLA } & \multirow[t]{2}{*}{ Average } & \multicolumn{2}{|l|}{$\mathrm{PE}$} & \multirow[t]{2}{*}{ Average } \\
\hline & $\mathrm{L}$ & $\mathrm{S}$ & & $\mathrm{L}$ & $\mathrm{S}$ & \\
\hline \multicolumn{7}{|l|}{ TS 2 h [\%] } \\
\hline 40 & $1.42^{\mathrm{bc}}$ & $0.82^{\mathrm{d}}$ & $1.12^{\mathrm{C}}$ & $1.37^{\mathrm{bc}}$ & $1.04^{\mathrm{cd}}$ & $1.21^{\mathrm{BC}}$ \\
\hline 50 & $2.20^{\mathrm{a}}$ & $1.62^{\mathrm{b}}$ & $1.91^{\mathrm{A}}$ & $1.34^{\mathrm{bc}}$ & $1.42^{\mathrm{bc}}$ & $1.38^{\mathrm{B}}$ \\
\hline 60 & $2.17^{\mathrm{a}}$ & $1.43^{\mathrm{bc}}$ & $1.80^{\mathrm{A}}$ & $2.29^{\mathrm{a}}$ & $1.49^{\mathrm{b}}$ & $1.89^{\mathrm{A}}$ \\
\hline Average & $1.91^{1}$ & $1.28^{3}$ & - & $1.67^{2}$ & $1.32^{3}$ & - \\
\hline \multicolumn{7}{|l|}{ TS $24 \mathrm{~h}[\%]$} \\
\hline 40 & $4.63^{\mathrm{abc}}$ & $2.98^{\mathrm{de}}$ & $3.80^{\mathrm{B}}$ & $2.12^{\mathrm{ef}}$ & $1.72^{\mathrm{f}}$ & $1.92^{\mathrm{C}}$ \\
\hline 50 & $3.90^{\mathrm{cd}}$ & $4.20^{\mathrm{bc}}$ & $4.05^{\mathrm{B}}$ & $2.16^{\mathrm{ef}}$ & $2.47^{\mathrm{ef}}$ & $2.31^{\mathrm{C}}$ \\
\hline 60 & $4.90^{\mathrm{abc}}$ & $5.19^{\mathrm{ab}}$ & $5.04^{\mathrm{A}}$ & $5.55^{\mathrm{a}}$ & $2.74^{\mathrm{e}}$ & $4.15^{\mathrm{B}}$ \\
\hline average & $4.46^{1}$ & $4.08^{1}$ & - & $3.28^{2}$ & $2.31^{3}$ & - \\
\hline \multicolumn{7}{|l|}{ WA 2 h [\%] } \\
\hline 40 & $0.96^{\mathrm{ef}}$ & $0.52^{\mathrm{g}}$ & $0.74^{\mathrm{D}}$ & $0.70^{\text {efg }}$ & $0.64^{\mathrm{fg}}$ & $0.67^{\mathrm{D}}$ \\
\hline 50 & $2.13^{\mathrm{b}}$ & $1.08^{\mathrm{de}}$ & $1.60^{\mathrm{B}}$ & $0.80^{\text {efg }}$ & $0.83^{\text {efg }}$ & $0.82^{\mathrm{D}}$ \\
\hline 60 & $1.70^{\mathrm{c}}$ & $3.76^{\mathrm{a}}$ & $2.73^{\mathrm{A}}$ & $1.46^{\mathrm{cd}}$ & $0.82^{\text {efg }}$ & $1.14^{\mathrm{C}}$ \\
\hline average & $1.59^{1}$ & $1.72^{1}$ & - & $0.99^{2}$ & $0.77^{3}$ & - \\
\hline \multicolumn{7}{|l|}{ WA $24 \mathrm{~h}[\%]$} \\
\hline 40 & $4.50^{\mathrm{d}}$ & $2.75^{\mathrm{e}}$ & $3.63^{\mathrm{C}}$ & $1.71 \mathrm{fg}$ & $1.05^{\mathrm{g}}$ & $1.38^{\mathrm{E}}$ \\
\hline 50 & $7.16^{\mathrm{bc}}$ & $4.23^{\mathrm{d}}$ & $5.70^{\mathrm{B}}$ & $2.25^{\mathrm{ef}}$ & $2.43^{\mathrm{ef}}$ & $2.34^{\mathrm{D}}$ \\
\hline 60 & $6.39^{c}$ & $11.24^{\mathrm{a}}$ & $8.81^{\mathrm{A}}$ & $7.44^{b}$ & $2.88^{\mathrm{e}}$ & $5.16^{\mathrm{B}}$ \\
\hline Average & $6.01^{1}$ & $5.90^{1}$ & & $3.80^{2}$ & $2.12^{3}$ & \\
\hline
\end{tabular}

$L$ large particles of bark-filler, $S$ small particles of bark-filler, $A, B, \ldots, a, b, \ldots, 1,2, \ldots$ homogenous groups the properties of MOR and $\mathrm{SH}$. It can therefore be concluded that these variants not only have similar properties, but also have the highest MOR and $\mathrm{SH}$ values. It should be emphasized that both variants were made of PLA. Points marking variants II and III have positive coordinates on the p1 axis, and the distance between them is small, which shows that in the case of PLA-based composites, the bark share within 50-60\% does not significantly affect strength properties. The size of the bark particles used to make the composite has a much greater impact in this case, as evidenced by the distance between the points denoting variants II and III as well as V and VI. In the case of points corresponding to variants of HDPEbased composites, it can be stated that they are characterized by relatively good strength properties, and the impact of bark share and the size of bark particles slightly differentiate the overall strength properties of these panels. This is evidenced by the fact that the points corresponding to the variants of 
Table 7 ANOVA for selected factors affecting TS and WA of manufactured boards

\begin{tabular}{|c|c|c|c|c|c|c|c|c|}
\hline \multirow[t]{3}{*}{ Source of variation } & \multicolumn{4}{|l|}{ TS } & \multicolumn{4}{|l|}{ WA } \\
\hline & \multicolumn{2}{|l|}{$2 \mathrm{~h}$} & \multicolumn{2}{|l|}{$24 \mathrm{~h}$} & \multicolumn{2}{|l|}{$2 \mathrm{~h}$} & \multicolumn{2}{|l|}{$24 \mathrm{~h}$} \\
\hline & $p$ & $P(\%)$ & $p$ & $P(\%)$ & $p$ & $P(\%)$ & $P$ & $P(\%)$ \\
\hline $\mathrm{a}$ & 0.022 & 1.36 & 0.000 & 27.97 & 0.000 & 20.27 & 0.000 & 27.64 \\
\hline $\mathrm{b}$ & 0.000 & 23.73 & 0.000 & 5.39 & 0.740 & 0.01 & 0.000 & 1.91 \\
\hline $\mathrm{c}$ & 0.000 & 31.39 & 0.000 & 27.51 & 0.000 & 30.72 & 0.000 & 39.69 \\
\hline$a \times b$ & 0.005 & 2.05 & 0.014 & 1.15 & 0.000 & 1.27 & 0.000 & 2.20 \\
\hline $\mathrm{a} \times \mathrm{c}$ & 0.000 & 8.16 & 0.003 & 2.28 & 0.000 & 11.67 & 0.000 & 1.06 \\
\hline $\mathrm{b} \times \mathrm{c}$ & 0.000 & 4.41 & 0.000 & 5.87 & 0.000 & 8.26 & 0.000 & 1.32 \\
\hline $\mathrm{a} \times \mathrm{b} \times \mathrm{c}$ & 0.020 & 2.07 & 0.000 & 10.17 & 0.000 & 20.04 & 0.000 & 21.47 \\
\hline Error & - & 26.85 & - & 19.68 & - & 7.75 & - & 4.72 \\
\hline
\end{tabular}

a matrix type/ composite, $\mathrm{b}$ size of bark particles, $c$ share of bark-filler, $p$ probability of error, $P$ percentage of contribution

Figure 4 Projection of the variables on the factor plane.

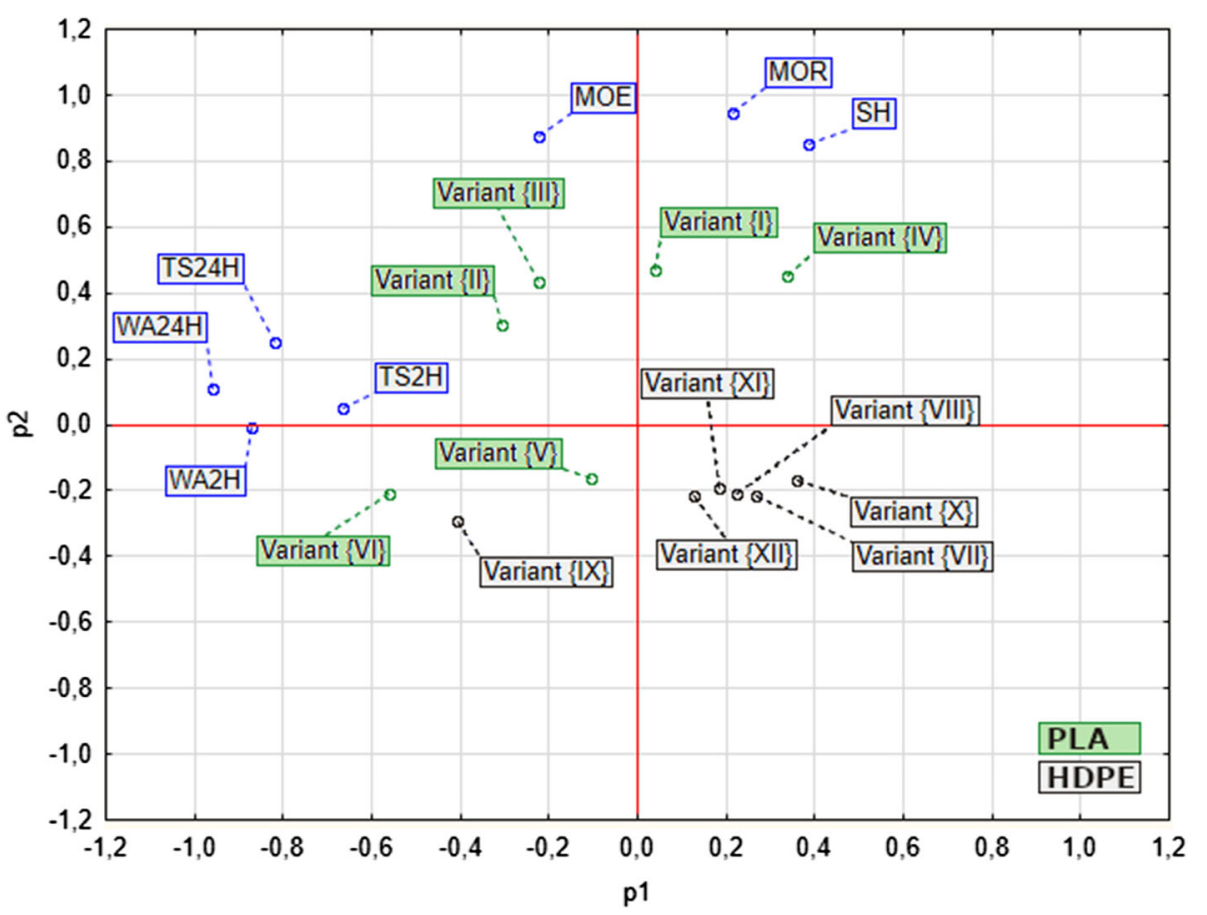

HDPE-based composites are located in the same quarter of the graph, at short distances from each other. Only the point denoting variant 10 with poor strength properties is located at a considerable distance from the other points denoting variants of HDPE-based composites.

\section{Conclusions}

The results obtained in the present study revealed a possibility to use pine bark as a filler in PLA composites. Composites with large filler particles were characterized by generally better mechanical and physical properties compared to composites with small particles of the filler.

It is noteworthy that both PLA composites with $40 \%$ content of bark had the best parameters. However, the increase in bark content from 40 to $60 \%$ in PLA composites resulted in a decrease of strength 
properties of the boards, wherein the decline was most significant in the case of composites with smaller bark particles. The thickness swelling and water absorbability increased as the filler content in the PLA composites increased, and a similar phenomenon was observed for the contact angle and surface energy.

In general, PLA composites were characterized by higher strength parameters and lower humidity resistance in comparison with HDPE composites with the same bark content. Furthermore, PLA composites showed greater surface contact angles with lower total surface energy values.

\section{Acknowledgements}

The presented research was financed under the "Strategic research and development program: environment, agriculture, and forestry" (BIOSTRATEG, Grant No. BIOSTRATEG3/344303/14/NCBR/2018). The funding institution was The National Centre for Research and Development

\section{Author contributions}

PB helped in investigation, conceptualization, methodology, formal analysis, writing-original draft, project administration; funding acquisition. PB helped in investigation, conceptualization, contribution to writing of original draft. RA helped in investigation, conceptualization, contribution to writing of original draft, formal analysis. AA contributed to formal analysis, visualization, writing-review and editing and LD involved in investigation, contribution to writing of original draft. MN and KR investigated the study.

\section{Funding}

This work was supported by The Polish National Centre for Research and Development [Grant No. BIOSTRATEG3/344303/14/NCBR/2018].

\section{Data and code availability}

Borysiuk, Piotr; Boruszewski, Piotr; Auriga, Radoslaw; Danecki, Leszek; Auriga, Alicja; Nowacka,
Małgorzata; Rybak, Katarzyna (2021), "Influence of a bark-filler on the properties of PLA biocomposites", Mendeley Data, V1, https://doi.org/10.17632/8dth prgk7p.1

\section{Compliance with ethical standards}

Conflict of interest The authors declare that they have no conflict of interest.

Open Access This article is licensed under a Creative Commons Attribution 4.0 International License, which permits use, sharing, adaptation, distribution and reproduction in any medium or format, as long as you give appropriate credit to the original author(s) and the source, provide a link to the Creative Commons licence, and indicate if changes were made. The images or other third party material in this article are included in the article's Creative Commons licence, unless indicated otherwise in a credit line to the material. If material is not included in the article's Creative Commons licence and your intended use is not permitted by statutory regulation or exceeds the permitted use, you will need to obtain permission directly from the copyright holder. To view a copy of this licence, visit http://creativecommons.org/licen ses/by/4.0/.

\section{References}

[1] Partanen A, Carus M (2019) Biocomposites, find the real alternative to plastic - An examination of biocomposites in the market. Reinf Plast 63:317-321. https://doi.org/10.1016/ j.repl.2019.04.065

[2] Markarian J (2008) Biopolymers present new market opportunities for additives in packaging. Plast Addit Compd 10:22-25. https://doi.org/10.1016/S1464-391X(08)70091-6

[3] Farah S, Anderson DG, Langer R (2016) Physical and mechanical properties of PLA, and their functions in widespread applications-A comprehensive review. Adv Drug Deliv Rev 107:367-392. https://doi.org/10.1016/j.addr.2016. 06.012

[4] Auras R, Harte B, Selke S (2004) An overview of polylactides as packaging materials. Macromol Biosci 4:835-864. h ttps://doi.org/10.1002/mabi.200400043

[5] Kuciel S, Liber-Kneć A, Mikuła J et al (2010) Kompozyty polimerowe na osnowie recyklatów z włóknami naturalnymi: praca zbiorowa. Politechnika Krakowska, Kraków

[6] Kim J-W, Harper DP, Taylor AM (2009) Effect of wood species on the mechanical and thermal properties of wood- 
plastic composites. J Appl Polym Sci 112:1378-1385. http s://doi.org/10.1002/app.29522

[7] Mohanty AK, Misra M, Drzal LT (2005) Natural Fibers, Biopolymers, and Biocomposites, vol 1. CRC Press, Boca Raton

[8] Saputra H, Simonsen J, Li K (2004) Effect of extractives on the flexural properties of wood/plastic composites. Compos Interfaces 11:515-524. https://doi.org/10.1163/ 1568554042722964

[9] Shebani AN, van Reenen AJ, Meincken M (2009) The effect of wood extractives on the thermal stability of different wood-LLDPE composites. Thermochim Acta 481:52-56. h ttps://doi.org/10.1016/j.tca.2008.10.008

[10] Chaharmahali M, Tajvidi M, Najafi SK (2008) Mechanical properties of wood plastic composite panels made from waste fiberboard and particleboard. Polym Compos 29:606-610. https://doi.org/10.1002/pc.20434

[11] Myers GE, Clemons CM (1993) Wastepaper fiber in plastic composites made by melt blending: demonstration of commercial feasibility. Final Report for Solid Waste Reduction and Recycling Demonstration Grant Program Project No 91-5

[12] Ashori A, Nourbakhsh A (2009) Characteristics of woodfiber plastic composites made of recycled materials. Waste Manag 29:1291-1295. https://doi.org/10.1016/j.wasman.20 08.09.012

[13] Harkin JM, Rowe JW (1971) Bark and its possible uses. US Dep Agric For Serv For Prod Lab, p 60

[14] Kunttu J, Hurmekoski E, Heräjärvi H et al (2020) Preferable utilisation patterns of wood product industries' by-products in Finland. For Policy Econ 110:101946. https://doi.org/10. 1016/j.forpol.2019.101946

[15] Yemele MCN, Blanchet P, Cloutier A, Koubaa A (2008) Effects of bark content and particle geometry on the physical and mechanical properties of particleboard made from black spruce and trembling aspen bark. For Prod J 58:48-56

[16] Blanchet P, Cloutier A, Riedl B (2000) Particleboard made from hammer milled black spruce bark residues. Wood Sci Technol 34:11-19. https://doi.org/10.1007/s002260050003

[17] Harper DP, Eberhardt TL (2010) Evaluation of Micron-Sized Wood and Bark Particles as Filler in Thermoplastic Composites. 10th International Conference on Wood Biofiber Plastic Composites, pp 248-252

[18] Yemele MCN, Koubaa A, Cloutier A et al (2010) Effect of bark fiber content and size on the mechanical properties of bark/HDPE composites. Compos Part A Appl Sci Manuf 41:131-137. https://doi.org/10.1016/j.compositesa.2009.06. 005
[19] Gozdecki C, Kociszewski M, Mirowski J, et al (2009) Effect of wood bark on wood-plastic composite properties. Ann Warsaw Univ Life Sci - SGGW For Wood Technol p 68

[20] Safdari V, Khodadadi H, Hosseinihashemi SK, Ganjian E (2011) The effects of poplar bark and wood content on the mechanical properties of wood-polypropylene composites. BioResources 6:5180-5192

[21] Kazemi Najafi S, Kiaefar A, Tajvidi M (2008) Effect of bark flour content on the hygroscopic characteristics of woodpolypropylene composites. J Appl Polym Sci 110:3116-3120. https://doi.org/10.1002/app.28852

[22] Peltola H, Pääkkönen E, Jetsu P, Heinemann S (2014) Wood based PLA and PP composites: Effect of fibre type and matrix polymer on fibre morphology, dispersion and composite properties. Compos Part A Appl Sci Manuf 61:13-22. https://doi.org/10.1016/j.compositesa.2014.02.002

[23] Georgiopoulos P, Kontou E, Christopoulos A (2015) Shortterm creep behavior of a biodegradable polymer reinforced with wood-fibers. Compos Part B Eng 80:134-144. https://d oi.org/10.1016/j.compositesb.2015.05.046

[24] Silva CG, Campini PAL, Rocha DB, Rosa DS (2019) The influence of treated eucalyptus microfibers on the properties of PLA biocomposites. Compos Sci Technol 179:54-62. h ttps://doi.org/10.1016/j.compscitech.2019.04.010

[25] Andrzejewski J, Szostak M, Barczewski M, Łuczak P (2019) Cork-wood hybrid filler system for polypropylene and poly(lactic acid) based injection molded composites. Structure evaluation and mechanical performance. Compos Part B Eng 163:655-668. https://doi.org/10.1016/j.compositesb.20 18.12.109

[26] Kamau-Devers K, Kortum Z, Miller SA (2019) Hydrothermal aging of bio-based poly(lactic acid) (PLA) wood polymer composites: Studies on sorption behavior, morphology, and heat conductance. Constr Build Mater 214:290-302. h ttps://doi.org/10.1016/j.conbuildmat.2019.04.098

[27] Gazzotti S, Rampazzo R, Hakkarainen M et al (2019) Cellulose nanofibrils as reinforcing agents for PLA-based nanocomposites: An in situ approach. Compos Sci Technol 171:94-102. https://doi.org/10.1016/j.compscitech.2018.12. 015

[28] Daver F, Lee KPM, Brandt M, Shanks R (2018) Cork-PLA composite filaments for fused deposition modelling. Compos Sci Technol 168:230-237. https://doi.org/10.1016/j.compsc itech.2018.10.008

[29] Ying-Chen Z, Hong-Yan W, Yi-Ping Q (2010) Morphology and properties of hybrid composites based on polypropylene/ polylactic acid blend and bamboo fiber. Bioresour Technol 101:7944-7950. https://doi.org/10.1016/j.biortech.2010.05. 007 
[30] Bledzki AK, Jaszkiewicz A, Scherzer D (2009) Mechanical properties of PLA composites with man-made cellulose and abaca fibres. Compos Part A Appl Sci Manuf 40:404-412. h ttps://doi.org/10.1016/j.compositesa.2009.01.002

[31] Petchwattana N, Covavisaruch S (2014) Mechanical and morphological properties of wood plastic biocomposites prepared from toughened poly(lactic acid) and rubber wood sawdust (hevea brasiliensis). J Bionic Eng 11:630-637. h ttps://doi.org/10.1016/S1672-6529(14)60074-3

[32] Mazzanti V, Pariante R, Bonanno A et al (2019) Reinforcing mechanisms of natural fibers in green composites: Role of fibers morphology in a PLA/hemp model system. Compos Sci Technol 180:51-59. https://doi.org/10.1016/j.compscite ch.2019.05.015

[33] Csizmadia R, Faludi G, Renner K et al (2013) PLA/wood biocomposites: Improving composite strength by chemical treatment of the fibers. Compos Part A Appl Sci Manuf 53:46-53. https://doi.org/10.1016/j.compositesa.2013.06. 003

[34] EN 310 (1994) Wood-based panels - determination of modulus of elasticity in bending and of bending strength. Brussels

[35] EN 320 (2011) Particleboards and fibreboards - determination of resistance to axial withdrawal of screws. Brussels

[36] EN 317 (1999) Particleboards and fibreboards - determination of swelling in thickness after immersion in water. Brussels

[37] Gurunathan T, Mohanty S, Nayak SK (2015) A review of the recent developments in biocomposites based on natural fibres and their application perspectives. Compos Part A Appl Sci Manuf 77:1-25. https://doi.org/10.1016/j.compo sitesa.2015.06.007

[38] Çetin NS, Özmen N, Narlıŏlu N, Çavuş V (2014) Effect of bark flour on the mechanical properties of HDPE composites. Usak Univ J Mater Sci 3:23-23. https://doi.org/10.127 48/uujms.201416497

[39] Gozdecki C, Kociszewski M (2008) Study of the screw withdrawal capacity in wood-polymer composites exposed to the accelerated ageing process. Ann Warsaw Univ Life Sci - SGGW For Wood Technol 65:84-87
[40] Falk RH, Vos DJ, Cramer SM, English BW (2001) Performance of fasteners in wood flour-thermoplastic composite panels. For Prod J 51:55-61

[41] Faludi G, Dora G, Renner K et al (2013) Improving interfacial adhesion in pla/wood biocomposites. Compos Sci Technol 89:77-82. https://doi.org/10.1016/j.compscitech.20 13.09.009

[42] de Meijer M, Haemers S, Cobben W, Militz H (2000) Surface energy determinations of wood: comparison of methods and wood species. Langmuir 16:9352-9359. https://doi.org/ 10.1021/la001080n

[43] Khoshkava V, Kamal MR (2013) Effect of surface energy on dispersion and mechanical properties of polymer/nanocrystalline cellulose nanocomposites. Biomacromol 14:3155-3163. https://doi.org/10.1021/bm400784j

[44] Hietala M, Niinimäki J, Oksman K (2011) Processing of wood chip-plastic composites: effect on wood particle size, microstructure and mechanical properties. Plast Rubber Compos 40:49-56. https://doi.org/10.1179/ 174328911X12988622800855

[45] Yew GH, Mohd Yusof AM, Mohd Ishak ZA, Ishiaku US (2005) Water absorption and enzymatic degradation of poly(lactic acid)/rice starch composites. Polym Degrad Stab 90:488-500. https://doi.org/10.1016/j.polymdegradstab.200 5.04 .006

[46] Wahit MU, Hassan A, Ibrahim AN et al (2015) Mechanical, thermal and chemical resistance of epoxidized natural rubber toughened polylactic acid blends. Sains Malaysiana 44:1615-1623

[47] Sillero L, Prado R, Andrés MA, Labidi J (2019) Characterisation of bark of six species from mixed Atlantic forest. Ind Crops Prod 137:276-284. https://doi.org/10.1016/j.indcrop. 2019.05.033

[48] Ribechini E, Mangani F, Colombini MP (2015) Chemical investigation of barks from broad-leaved tree species using EGA-MS and GC/MS. J Anal Appl Pyrolysis 114:235-242. https://doi.org/10.1016/j.jaap.2015.06.001

Publisher's Note Springer Nature remains neutral with regard to jurisdictional claims in published maps and institutional affiliations. 